\title{
頸動脈狭窄症における頸部血管造影超音波検査所見と予後の関連
}

\author{
植村 順一 ${ }^{1,2)}$, 大山 直紀 ${ }^{2)}$, 合田 敏章 ${ }^{2)}$, 岩本 高典 ${ }^{2)}$, 山下 眞史 ${ }^{1,2)}$, 井上 剛 ${ }^{1,2)}$, 八木田 佳樹 ${ }^{2)}$ \\ 1) 川崎医科大学総合医療センター脳卒中科 \\ 2) 川崎医科大学脳卒中医学教室
}

\section{Association between contrast-enhanced ultrasonography findings and prognosis in patients with carotid stenosis}

\author{
Junichi UEMURA ${ }^{1,2)}$, Naoki OYAMA ${ }^{2)}$, Toshiaki GODA ${ }^{2)}$, Takanori IWAMOTO $^{2)}$, Shinji YAMASHITA ${ }^{1,2)}$, \\ Takeshi INOUE $^{1,2)}$, Yoshiki YAGITA ${ }^{2)}$ \\ 1) Department of Stroke Medicine, Kawasaki Medical School General Medical Center \\ 2) Department of Stroke Medicine, Kawasaki Medical School
}

\begin{abstract}
Background: The characteristics of carotid plaque strongly influence the potential risk of stroke. However, few studies have followed up patients with carotid characteristics using contrast-enhanced ultrasonography (CEUS). Objective and Methods: Between July 2015 and September 2017, we enrolled 50 patients with carotid stenosis who underwent carotid ultrasonography (CUS), CEUS, and black-blood magnetic resonance imaging (BB-MRI) to evaluate the carotid characteristics. We assessed the correlation between enhancement-positive, ulcer-positive, T1-high, and recurrence or ipsilateral ischemic stroke or death.

Results: Of the 50 patients hospitalized for carotid stenosis, 8 (16\%) developed recurrence of ipsilateral ischemic stroke or died in the first year of follow-up. In the ulcer-positive group, the recurrence or death rate was 35\% $(6 / 17)$ during the first year, which was statistically different from that in the ulcer-negative group $(p<0.05)$. Conclusions: Follow-up by CEUS in patients with ulcer-positive carotid plaque can provide valuable information regarding ipsilateral ischemic recurrences or death.
\end{abstract}

Keywords: contrast-enhanced ultrasonography, black-blood magnetic resonance imaging, internal carotid artery stenosis

(Received May 23, 2019; Accepted July 31, 2019)

\section{はじめに}

頸部血管超音波検査は, 頸動脈狭窄病変の不安定プ ラークや潰瘍病変を簡便かつ低侵襲に検出することがで きる。一方，頸部血管超音波検査におけるプラーク輝度 の評価や潰瘍形成の検出は，検者の技量に左右されるた め，再現性，客観性などの点で不十分な場合もある。近 年, 超音波造影剂を使用した頸動脈狭窄病変不安定プ ラーク評価が注目されている ${ }^{1-8)}$.

その他の頸動脈狭窄病変の評価のモダリティとして は, black-blood MRI（BB-MRI）があり, BB-MRI T1 高信号による頸動脈狭窄病変部の不安定プラーク評価が
可能である ${ }^{9)}$. BB-MRI T1 高信号病変が同側の脳卒中 発症リスクになると報告されている ${ }^{10,11)}$.

われわれは内頸動脈狭窄症（internal carotid artery stenosis：ICAS）例に対し, 頸動脈超音波検査（carotid ultrasonography：CUS）, 頸部血管造影超音波検査（contrast-enhanced ultrasonography: CEUS) と BB-MRI を 行って狭窄度と頸動脈プラークの不安定性を評価し, 1 年後の同一血管支配領域の脳梗塞再発あるいは死亡を予 測できるかどうかを検討した。

方法

2015 年 7 月から 2017 年 9 月までにCUS, CEUS,

\section{Reprint request}

植村順一： ₹ 700-8505 岡山県岡山市北区中山下 2-6-1 川崎医科大学総合医療センター脳卒中科

Junichi UEMURA: Department of Stroke Medicine, Kawasaki Medical School General Medical Center, 2-6-1, Nakasange, Kita-ku, Okayama 7008505, Japan

E-mail: uemuratrail@yahoo.co.jp, Tel: 086-225-2111, Fax: 086-232-8343 
Table 1 Characteristics of the patients during the 1-year follow-up

\begin{tabular}{lcccc}
\hline & $\begin{array}{c}\text { Total } \\
(\boldsymbol{n}=\mathbf{5 0})\end{array}$ & $\begin{array}{c}\text { Recurrence or death } \\
(\boldsymbol{n}=\mathbf{8})\end{array}$ & $\begin{array}{c}\text { No recurrence or death } \\
(\boldsymbol{n}=\mathbf{4 2})\end{array}$ & $\boldsymbol{p}$ \\
\hline Age (years, mean) & $71 \pm 11.8$ & $79 \pm 8.3$ & $70 \pm 11.7$ & $<0.05$ \\
Male, $n$ (\%) & $41(76)$ & $3(34)$ & $38(90)$ & 0.62 \\
Hypertension, $n(\%)$ & $33(66)$ & $6(75)$ & $27(64)$ & 0.15 \\
Hyperlipidemia, $n(\%)$ & $27(54)$ & $3(38)$ & $24(39)$ & 0.83 \\
Diabetes mellitus, $n(\%)$ & $19(38)$ & $4(50)$ & $15(36)$ & 0.63 \\
Smoking, $n(\%)$ & $31(62)$ & $4(50)$ & $27(65)$ & 0.57 \\
Symptomatic ischemia, $n(\%)$ & $38(76)$ & $4(50)$ & $34(81)$ & 0.26 \\
\hline
\end{tabular}

Data are represented as mean \pm standard deviation or number of patients (\%).

BB-MRI による狭窄率とプラーク性状の評価を施行され た ICAS 症例のうち, 外科的加療〔carotid endarterectomy (CEA), carotid artery stenting (CAS)]された症 例と radiation-induced carotid stenosis と診断された症例 を除外し，それ以外の内科的加療された症例を対象とし た。頸動脈狭窄症を有し，かつ同側頸動脈支配領域に一 致する一過性脳虚血発作, 脳梗塞または一過性黒内障で 入院した場合を症候性脳梗塞ありと定義した。頸動脈狭 窄以外の塞栓源を検索するために経胸壁心エコー, 24 時間心電図, 経食道心エコーを施行し， 3 人の脳卒中専 門医の診断で心原性脳塞栓症，大動脈原性脳梗塞と診断 したものは徐外した，超音波装置は HI VISION Preirus （日立製作所，東京）リニア型 $5 \sim 12 \mathrm{MHz}$ を使用し, ICAS 病変を観察した。CUS で内頸動脈起始部最狭窄部 の血流速度がミ200cm/s を高度狭窄群, $150 \sim 200 \mathrm{~cm} / \mathrm{s}$ を中等度狭窄群， $<150 \mathrm{~cm} / \mathrm{s}$ を軽度狭窄群とした ${ }^{12)}$. CEUS は同じく HI VISION Preirus 超音波装置，プロー ブはリニア型 5〜 $12 \mathrm{MHz}$ で MI 值 0.20 , ハーモニック コントラストイメージングに設定し, 超音波造影剤はソ ナゾイド ${ }^{\circledR}$ (第一三共, 東京) $0.015 \mathrm{ml} / \mathrm{kg}$ を使用した。 ソナゾイド ${ }^{\circledR}$ は卵アレルギーがある症例にはアレルギー 症状を誘発するおそれがあり，原則禁忌である。副作用 は下痢（1％）程度であるが ICAS 例に対する保険適用 がなく, 1 回 13,000 円程度の費用がかかる。われわれ の施設では倫理委員会の承認を得て使用した（承認No. 2246-3).

本人あるいは家族からの十分なインフォームドコンセ ントを得て使用した。新生血管を示唆するとされるプ ラーク造影は既報 ${ }^{1)}$ に従い, 造影なし, 造影 I 度, II 度 と分類した。潰瘍病変はプラーク表面から深さ $2 \mathrm{~mm}$ 以 上の掘れ込みとした ${ }^{13)}$ 。頸動脈プラーク評価は $1.5 \mathrm{~T}$ (tesla)-MRI (Philips Medical Systems) あるいは 3T-MRI T1 強調画像水平断, 冠状断による BB-MRI T1 高信号で評価した。ワークステーション上において，同 一スライス上でプラークと近傍胸鎖乳突筋の信号比プ ラーク / 筋肉信号強度比 (plaque muscle ratio : $\mathrm{P} / \mathrm{M}$ 比)
を検出し， 1.4 以上を高信号とした ${ }^{11)}$. 1 年後に診察を 行い，その時点の同一血管支配領域での脳梗塞再発ある いは死亡の有無, modified Rankin Scale（m-RS）を確 認した。死亡例は，カルテ情報，電話，手紙での家族へ の調査で死亡時期，死亡原因を確認した，年歯令，脳梗塞 リスク, 症候性脳梗塞の有無, CUS での ICAS 狭窄度, CEUS での造影度, 潰瘍有無, BB-MRI T1 高信号有無と, 1 年後の同一血管支配領域での脳梗塞再発あるいは死亡 との関係を比較した，検定は Mann-Whitney U 検定あ るいは $\chi^{2}$ 検定, Kaplan-Meier 曲線は log-rank test で行い, $p<0.05$ を有意とした。統計ソフトはSPSS Statistics ver. 17.0 for Windows（SPSS, Inc., Chicago, Illiois）を使 用した。

\section{結果}

対象は ICAS 135 例中, CEA 30 例，CAS 51 例，radiation-induced carotid stenosis 4 例を除外した 50 例で, 性別は男性 41 例 $(82 \%)$ ，年齢は 59～83 歳（中央値 71 歳), 症候性 ICAS 38 例 $(76 \%), 1$ 年以内の同一血 管支配領域再発あるいは死亡は 8 例（16\%）であった。 CUS では高度狭窄 14 例 (28\%), 中等度狭窄 5 例 (10\%), 軽度狭窄 31 例 $(62 \%)$ であり，CEUS で造影 I 度は 15 例 $(30 \%)$ ， II 度 4 例（8\%)，潰瘍病変を認めたのは 15 例（34\%）であった。 また BB-MRI T1 高信号だったの は24例（48\%）であった。 1 年間の同一血菅支配領域 脳梗塞再発あるいは死亡は，年齢が高いほど有意に高 かった（ $p<0.05 ） （$ Table 1). 1 年間の同一血菅支配領 域における脳梗塞再発あるいは死亡は, 高度狭窄・中等 度狭窄・軽度狭窄で有意差はなかった $(p=0.23$ ) (Table 2). 造影所見による 1 年間の同一血菅支配領域脳梗塞再発 あるいは死亡は，造影 I 度・II 度・なしで有意差を認め なかった $(p=0.63)$ （Table 2$)$ ．潰瘍病変による 1 年間 の同一血菅支配領域脳梗塞再発あるいは死亡は，潰瘍あ り・なしで有意差を認めた（ $p<0.05 ）$ (Table 2). BBMRI T1 高信号による同一血菅支配領域脳梗塞再発ある いは死亡は, T1 高信号あり・なしで有意差を認めなかっ 
Table 2 Carotid stenosis, enhancement grade, ulcer with contrast-enhanced ultrasonography and T1 high with black-blood magnetic resonance imaging of recurrence or death during the 1-year follow-up

\begin{tabular}{lcccc}
\hline & $\begin{array}{c}\text { Total } \\
(\boldsymbol{n}=\mathbf{5 0})\end{array}$ & $\begin{array}{c}\text { Recurrence or death } \\
(\boldsymbol{n}=\mathbf{8})\end{array}$ & $\begin{array}{c}\text { No recurrence or death } \\
(\boldsymbol{n}=\mathbf{4 2})\end{array}$ & $\boldsymbol{p}$ \\
\hline CUS stenosis & & & & 0.23 \\
$\quad$ Severe, $n(\%)$ & $14(28)$ & $1(13)$ & $13(31)$ & \\
$\quad$ Moderate, $n(\%)$ & $5(10)$ & $2(25)$ & $3(7)$ & \\
$\quad$ Mild, $n$ (\%) & $31(62)$ & $5(63)$ & $26(62)$ & \\
CEUS enhancement & $15(30)$ & $3(38)$ & $12(29)$ & $4(10)$ \\
$\quad$ Grade I, $n$ (\%) & $4(8)$ & $0(0)$ & $11(26)$ & $<0.05$ \\
$\quad$ Grade II, $n(\%)$ & $17(34)$ & $6(75)$ & $20(83)$ & 0.90 \\
CEUS ulcer, $n(\%)$ & $24(48)$ & $4(50)$ & \\
BB-MRI, T1 high, $n(\%)$ & &
\end{tabular}

CUS, carotid ultrasonography; CEUS, contrast-enhanced ultrasonography; BB-MRI, black-blood MRI.

Data are represented as number of patients (\%).

Table 3 Enhancement grade with contrast-enhanced ultrasonography and T1 high with black-blood MRI of ulcer with contrast-enhanced ultrasonography

\begin{tabular}{lcccc}
\hline & $\begin{array}{c}\text { Total } \\
(\boldsymbol{n}=\mathbf{5 0})\end{array}$ & $\begin{array}{c}\text { CEUS ulcer } \\
(\boldsymbol{n}=\mathbf{1 7})\end{array}$ & $\begin{array}{c}\text { No CEUS ulcer } \\
(\boldsymbol{n}=\mathbf{3 3})\end{array}$ & $\boldsymbol{p}$ \\
\hline CEUS enhancement & & & & 0.11 \\
Grade I, $n$ (\%) & $17(34)$ & $7(41)$ & $10(30)$ & \\
Grade II, $n$ (\%) & $4(8)$ & $3(18)$ & $1(3)$ & $<0.05$ \\
BB-MRI T1 high, $n(\%)$ & $24(48)$ & $12(71)$ & $12(36)$ & \\
\hline
\end{tabular}

CEUS, contrast-enhanced ultrasonography; BB-MRI, black-blood MRI.

Data are represented as number of patients (\%).

た（ $p=0.90 ） （$ Table 2). CEUS の潰瘍有無は, 造影度 と有意な関係を示さなかったが $(p=0.11), \mathrm{BB}-\mathrm{MRI}$ $\mathrm{T} 1$ 高信号との有意な関係を示した $(p<0.05)$ (Table 3). 潰瘍の有無による Kaplan-Meier曲線を Fig. 1 に示す $(p<0.05)$.

\section{考察}

本検討では内頸動脈狭窄病変に対して，CEUSによる 潰瘍病変の検出が同側の脳梗塞再発・死亡を予測する因 子となりうることが示された. CEUSによる造影病変が プラーク内の新生血管を描出していることは，CEA を 施行された症例での比較検討で多数報告されている ${ }^{2-5)}$. プラーク内新生血管の存在はプラーク不安定性を意味 し, 同側の脳梗塞再発の予測因子となりうると考えられ た。しかし，本検討では 1 年後の同側脳梗塞再発・死 亡で有意差はみられず，さらなるフォローアップが必要 である. CEUSはCUSより明瞭に潰瘍病変を検出する ことができ，潰瘍病変がある症例は BB-MRIT1 高信号 であることが有意に多かった。CUS で潰瘍病変を認め ると同側脳梗塞再発リスクの予測が高く ${ }^{14,15)}$, CEUS で の潰瘍病変の検出が同側の脳梗塞再発リスク予測に有効 であれば，CEUS は簡便にベッドサイドで何度も施行で き非常に有用である。

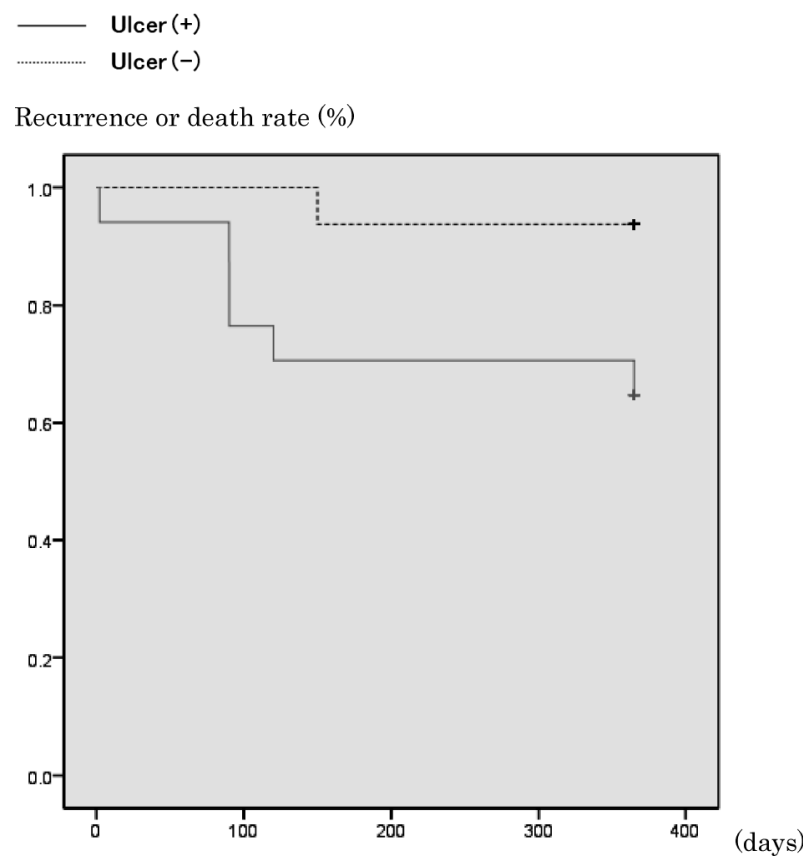

Fig. 1 Kaplan-Meier curve at 1 year

We compared the two groups, for no recurrence or death and presence of ulcer on contrast-enhanced ultrasonography using the Kaplan-Meier curve and tested for significance using the log-rank test $(p<0.05)$. 
ICAS 症例のプラーク不安定性評価に BB-MRI T1 高 信号が同側の脳梗塞再発に関係していると報告されてい る ${ }^{11)}$. Yoshidaらはさらに, CEA 施行された病理標本 を使用し BB-MRI T1 高信号に描出されるプラーク内出 血や expansive arterial remodeling が，抗血小板薬の多剂 併用やスタチン追加などの強力な内科加療でも同側脳梗 塞を再発しやすかったことを報告している ${ }^{10)}$.

本研究には限界がある。1つは外科的加療施行例の予 後を追跡できなかったため，狭窄率，造影度が高い症例 を研究に組み入れることができなかった点である．2つ 目はフォローアップ期間が十分でなかった点が挙げられ る.

本研究により CEUS での潰瘍病変は, ICAS 症例に対 する内科的加療の際の脳梗塞再発あるいは死亡を予測す る因子となる可能性が示唆された。ささらなる症例の蓄積 とフォローアップが必要である.

利益相反：著者全員が本論文に対して利益相反なし．

\section{○文献}

1) Deyama J, Nakamura T, Takishima I, et al.: Contrast-enhanced ultrasound imaging of carotid plaque neovascularization is useful for identifying high-risk patients with coronary artery disease. Circ J 2013; 77:1499-1507.

2) Saito $K$, Nagatsuka $K$, Ishibashi-Ueda $H$, et al.: Contrastenhanced ultrasound for the evaluation of neovascularization in atherosclerotic carotid artery plaques. Stroke 2014; 45: 30733075 .

3) Matsumoto N, Kimura K, Uno M, et al.: Enhanced carotid plaque on contrast-enhanced ultrasound is associated with plaque instability and rupture. Int J Stroke 2011; 7: E12.

4) Shah F, Balan P, Weinberg $M$, et al.: Contrast-enhanced ultrasound imaging of atherosclerotic carotid plaque neovascularization: a new surrogate marker of atherosclerosis?
Vasc Med 2007; 12: 291-297.

5) Hoogi A, Adam D, Hoffman A, et al.: Carotid plaque vulnerability: Quantification of neovascularization on contrastenhanced ultrasound with histopathologic correlation. AJR Am Roentgenol 2011; 196: 431-436.

6) Staub D, Partovi S, Imfeld S, et al.: Novel applications of contrast-enhanced ultrasound imaging in vascular medicine. Vasa 2013; 42: 17-31.

7) Saha SA, Gourineni V, Feinstein SB: The use of contrastenhanced ultrasonography for imaging of carotid atherosclerotic plaques: Current evidence, future directions. Neuroimaging Clin N Am 2016; 26: 81-96.

8) Filis K, Toufektzian L, Galyfos G, et al.: Assessment of the vulnerable carotid atherosclerotic plaque using contrastenhanced ultrasonography. Vascular 2017; 25: 316-325.

9) Yoshida K, Narumi O, Chin M, et al.: Characterization of carotid atherosclerosis and detection of soft plaque with use of black-blood MR imaging. AJNR Am J Neuroradiol 2008; 29: 868-874.

10) Yoshida K, Sadamasa N, Narumi O, et al.: Symptomatic lowgrade carotid stenosis with intraplaque hemorrhage and expansive arterial remodeling is associated with a high relapse rate refractory to medical treatment. Neurosurgery 2012; 70: 1143-1151.

11) Kurosaki Y, Yoshida K, Fukumitsu R, et al.: Carotid artery plaque assessment using quantitative expansive remodeling evaluation and MRI plaque signal intensity. J Neurosurg 2016; 124: 736-742.

12) Kimura K, Yonemura K, Terasaki $T$, et al.: Duplex carotid sonography in distinguishing acute unilateral atherothrombotic from cardioembolic carotid artery occlusion. AJNR Am J Neuroradiol 1997; 18: 1447-1452.

13）長束一行：頸部頸動脈狭窄の超音波診断, 日本脳神経超音波 学会機関誌 Neurosonology 編集委員会（編）：日本脳神経超 音波学会脳神経超音波マニュアル，島根：報光社，2006， p106-113.

14) Handa $N$, Matsumoto $M$, Maeda $H$, et al.: Ischemic stroke events and carotid atherosclerosis. Results of the osaka follow-up study for ultrasonographic assessment of carotid atherosclerosis (the Osaca study). Stroke 1995; 26: 1781-1786.

15）半田伸夫，岡崎裕，伊藤泰司，他：頸動脈超音波検查による 頸動脈プラークの組織性状診断と脳梗塞発症との関係. Neurosonology 2000; 13: 170-174. 